\title{
Mass-Spectrometric Study of Molecular and Ionic Sublimation of Gadolinium and Terbium Tribromides in Knudsen and Langmuir Modes
}

\author{
L. S. Kudin, V. B. Motalov, M. F. Butman, S. N. Nakonechnyi, and K. B. Kremer \\ Ivanovo State University of Chemical Engineering, Ivanovo, Russia \\ Bern University, Bern, Switzerland
}

Received February 25, 2010

\begin{abstract}
Molecular and ionic sublimation of gadolinium and terbium tribromides in Knudsen and Langmuire modes was studied by the method of high-temperature mass-spectrometry. On the basis of obtained enthalpies of sublimation and ion-molecule reactions the enthalpies of formation of $\mathrm{LnBr}_{3}$ and $\mathrm{Ln}_{2} \mathrm{Br}_{6}$ molecules and $\mathrm{LnBr}_{4}^{-}$and $\mathrm{Ln}_{2} \mathrm{Br}_{7}^{-}$negative ions were determined. For the first time the electron work function for crystals of the studied tribromides was calculated.
\end{abstract}

DOI: $10.1134 / \mathrm{S} 1070363211010063$

The systematic study of thermodynamics and kinetics of the molecular and ionic sublimation of tribromide of certain lanthanides was started in [1-6].

Saturated vapor pressures above $\mathrm{GdBr}_{3}$ and $\mathrm{TbBr}_{3}$ were measured earlier by the boiling point $[7,8]$, massspectrometry [9], and torsion-effusion [10] methods, and also by the static methods [11] $\left(\mathrm{GdBr}_{3}\right)$. Except for [9], where dimeric molecules were detected in vapor, in the above-mentioned works the total pressure was measured, and the data were treated on the assumption that only monomeric molecules are present in the vapor.

In this work new experimental data on the vapor pressure together with available published data including an updated set of thermodynamic functions were used for the calculation of the enthalpy of sublimation of gadolinium and terbium tribromides in the form of monomeric and dimeric molecules. On the basis of the examination of the obtained results thermodynamic parameters of monomeric and dimeric molecules were recommended.

Thermodynamics of ionic sublimation of the specified tribromides was studied for the first time, equilibrium constants were measured and enthalpies of ion-molecule reactions were calculated, and enthalpies of formation of negative ions $\mathrm{LnBr}_{4}^{-}$and $\mathrm{Ln}_{2} \mathrm{Br}_{7}^{-}$ (hereinafter $\mathrm{Ln}=\mathrm{Gd}$, $\mathrm{Tb}$ ) were determined on their basis.

In addition to the thermodynamic studies we have studied for the first time the kinetics of sublimation of $\mathrm{GdBr}_{3}$ and $\mathrm{TbBr}_{3}$ single crystals in Langmuir mode (evaporation from an open surface) and have determined the activation energies of their sublimation in the form of monomeric and dimeric molecules and also of negative ions $\mathrm{LnBr}_{4}^{-}$and $\mathrm{Ln}_{2} \mathrm{Br}_{7}^{-}$in Knudsen mode (evaporation under equilibrium conditions) from temperature dependences of ionic currents.

Measuremednts of molecular sublimation in Knudsen mode. In the mass spectra of vapor above gadolinium and terbium tribromides (Table 1) in the temperature ranges 878-1044 and 860-1067 K, respectively, similarly to other tribromides [1-6, 9], the following ions were identified: $\mathrm{Ln}^{+}, \mathrm{LnBr}^{+}, \mathrm{LnBr}_{2}^{+}$, $\mathrm{LnBr}_{3}^{+}, \mathrm{Ln}_{2} \mathrm{Br}_{4}^{+}, \mathrm{Ln}_{2} \mathrm{Br}_{5}^{+}$, and $\mathrm{Tb}_{3} \mathrm{Br}_{8}^{+}$. Except for the enumerated ions, two-charge ions $\mathrm{Ln}^{++}, \mathrm{LnBr}^{++}$, and $\mathrm{LnBr}_{2}^{++}$making a $\sim 3 \%$ contribution to the total ionic current were recorded.

The standard procedure of correlating detected ions to their molecular precursors [analysis of forms of ionization effectiveness curves (IEC) for various ions, measuring appearance energies of ions by the method of linear extrapolation of IEC near-threshold sections (Table 1), and determination of coefficients of tem- 
Table 1. Mass spectra taken at the ionization by electrons in Knudsen and Langmuir modes and appearance energies of ions (AE)

\begin{tabular}{|c|c|c|c|c|c|c|c|c|}
\hline Value & Mode & $\mathrm{Ln}^{+}$ & $\mathrm{LnBr}^{+}$ & $\mathrm{LnBr}_{2}^{+}$ & $\mathrm{LnBr}_{3}^{+}$ & $\mathrm{Ln}_{2} \mathrm{Br}_{4}^{+}$ & $\mathrm{Ln}_{2} \mathrm{Br}_{5}^{+}$ & References \\
\hline \multicolumn{9}{|c|}{$\operatorname{GdBr}_{3}(T 901 \mathrm{~K})^{\mathrm{a}}$} \\
\hline \multirow{2}{*}{$\begin{array}{l}\text { Relative ionic } \\
\text { current } I, \text { b } \%\end{array}$} & Knudsen & 11.1 & 9.9 & 100 & 41.0 & 0.7 & 9.2 & This work \\
\hline & Langmuir & 11.6 & 7.4 & 100 & 12.5 & & 0.6 & \\
\hline \multirow[t]{2}{*}{$A E, \mathrm{eV}$} & & 19.9 & 14.3 & 11.6 & 10.0 & & 10.4 & This work \\
\hline & & 20.1 & 15.2 & 11.3 & 10.5 & & 11.0 & [9] \\
\hline \multicolumn{9}{|c|}{$\mathrm{TbBr}_{3}(T 905 \mathrm{~K})$} \\
\hline \multirow{2}{*}{$\begin{array}{l}\text { Relative ionic } \\
\text { current } I, \%\end{array}$} & Knudsen & 23.1 & 14.2 & 100 & 45.9 & 0.1 & 6.3 & This work \\
\hline & Langmuir & 16.7 & 20.7 & 100 & 32.3 & 0.2 & 2.9 & \\
\hline \multirow[t]{2}{*}{$A E, \mathrm{eV}$} & & 18.8 & 14.3 & 11.0 & 10.2 & & 11.6 & This work \\
\hline & & 19.7 & 15.1 & 11.3 & 10.5 & & 11.1 & [9] \\
\hline
\end{tabular}

Table 2. Coefficients of the equation $\log p(\mathrm{~Pa})=-A \times 10^{3} / T+B$

\begin{tabular}{c|c|c|c|c|c|c}
\hline \multirow{2}{*}{$\mathrm{Ln}$} & \multicolumn{3}{|c|}{$\mathrm{LnBr}_{3}$} & \multicolumn{3}{c}{$\operatorname{Ln}_{2} \mathrm{Br}_{6}$} \\
\cline { 2 - 7 } & $T, \mathrm{~K}$ & $A$ & $B$ & $T, \mathrm{~K}$ & $A$ & $B$ \\
\hline $\mathrm{Gd}$ & $878-1044$ & $14.43 \pm 0.35$ & $14.99 \pm 0.37$ & $907-1043$ & $18.74 \pm 0.57$ & $18.02 \pm 0.61$ \\
$\mathrm{~Tb}$ & $860-1064$ & $14.29 \pm 0.27$ & $14.44 \pm 0.29$ & $898-1063$ & $18.46 \pm 0.37$ & $17.33 \pm 0.37$ \\
\hline
\end{tabular}

perature dependences of ionic currents] suggested that ions with one lanthanide atom are formed preferentially on the ionization of monomeric molecules $\mathrm{LnBr}_{3}$, whereas the ions $\mathrm{Ln}_{2} \mathrm{Br}_{4}^{+}, \mathrm{Ln}_{2} \mathrm{Br}_{5}^{+}$, and $\mathrm{Tb}_{3} \mathrm{Br}_{8}^{+}$ are products of the dissociative ionization of dimeric molecules $\mathrm{Ln}_{2} \mathrm{Br}_{6}$ and trimeric molecules $\mathrm{Tb}_{3} \mathrm{Br}_{9}$, respectively.

Partial pressures of molecules $\left(p_{i}\right)$ in vapor were calculated by Eq. (1).

$$
p_{i}=\frac{k I_{i} T}{\sigma_{i}^{\mathrm{mol}}} .
$$

Here $(k)$ is a constant of the instrument sensitivity (determined in a special experiment on the vaporization of metal silver), $(T)$ is a temperature of a cell, $\mathrm{I}_{\mathrm{i}}=\Sigma I i_{j} /\left(a_{j} \gamma_{j}\right)$ is a total ionic current of all types of ions formed by the ith molecule, $(a)$ is a coefficient considering natural abundance of isotopes of the measured ion, $(\gamma)$ is a coefficient of the ion-electron conversion \{we accepted $\gamma \sim \mathrm{M}^{-1 / 2}[12],(M)$ is a molecular weight of an ion $\},\left(\sigma_{i}^{\mathrm{mol}}\right)$ is a total cross- section of the $i$ th molecule ionization at the working energy of ionizing electrons (calculated on the basis of the ionization cross-sections of atoms $\sigma^{\text {at }}$ [13] by the expression $\left.\sigma^{\mathrm{mol}}=0.75 \Sigma \sigma_{j}^{\mathrm{at}}[14]\right)$.

Temperature dependences of saturated vapor pressures of monomeric and dimeric molecules are approximated by linear equations $\log p=-A \times 10^{3} / T+$ $B$ with the coefficients given in Table 2 .

Partial pressures of components of saturated vapor above gadolinium and terbium tribromides together with the mass-spectrometric data of [9], and also with the data on the total pressure $[7,8,10,11]$ are shown in Figs. 1 and 2. It is seen from the figures that all the data on vapor pressures above $\mathrm{GdBr}_{3}$ and $\mathrm{TbBr}_{3}$ are located within the limits not exceeding an order of magnitude. For $\mathrm{GdBr}_{3}$ our data agree better with the mass-spectrometric data [9], and for $\mathrm{TbBr}_{3}$ - with the data obtained by the effusion-torsion method [10]. In the latter case our data on the pressures of both monomers and dimers are lower by a factor 2-3 than the pressures measured in [9], whereas the monomer: 


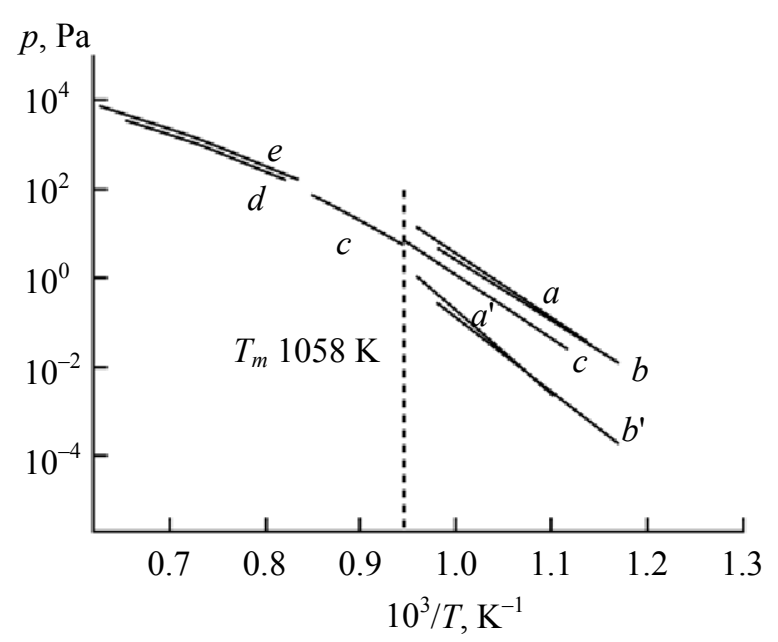

Fig. 1. Temperature dependences of vapor pressure above $\mathrm{GdBr}_{3}:(a)$ monomer, $\left(a^{\prime}\right)$ dimer, this work, $(b)$ monomer, $\left(b^{\prime}\right)$ dimer, [9], (c) [11], (d) [8,9], (e) [7].

dimer ratios in the both works are close to each other. The fraction of dimeric molecules in the studied temperature range for the studied tribromides does not exceed $6 \%$.

Enthalpies of $\mathrm{LnBr}_{3}$ sublimation in the form of monomeric and dimeric molecules were calculated by Eqs. (2) and (3).

$$
\begin{gathered}
\Delta_{\mathrm{r}} H^{0}(T)=-R \frac{\partial \ln K_{\mathrm{p}}(T)}{\partial(1 / T)}, \\
\Delta_{\mathrm{r}} H^{0}(0)=T\left[\Delta_{\mathrm{r}} \Phi^{0}(T)-R \ln K_{\mathrm{p}}(T)\right] .
\end{gathered}
$$

Here $\Delta_{\mathrm{r}} H^{0}(0), \Delta_{\mathrm{r}} H^{0}(T)$, and $\Delta_{\mathrm{r}} \Phi^{0}(T)$ are changes of the reaction enthalpy and the reduced Gibbs energy at temperatures 0 and $T \mathrm{~K}$, respectively, $(R)$ the gas constant, and $\left(K_{\mathrm{p}}\right)$ is the reaction equilibrium constant.

Thermodynamic functions of $\mathrm{TbBr}_{3}$ in the condensed state necessary for the calculations were taken from [15] and those of $\mathrm{GdBr}_{3}$, from the database [16]. Thermodynamic functions of monomeric $\mathrm{LnBr}_{3}$ molecules in the ideal gas state were calculated in the "rigid rotator-harmonic oscillator" approximation using molecular constants recommended on the basis of the examination of available results of the experimental and theoretical studies [17]. Functions of $\mathrm{Ln}_{2} \mathrm{Br}_{6}$ dimeric molecules were estimated by a comparative method by analogy with $\mathrm{Lu}_{2} \mathrm{Br}_{6}$ [2]. The thermodynamic functions used in the calculations are given in Table 3.

The results of processing the whole combination of the experimental data fulfilled with the use of a

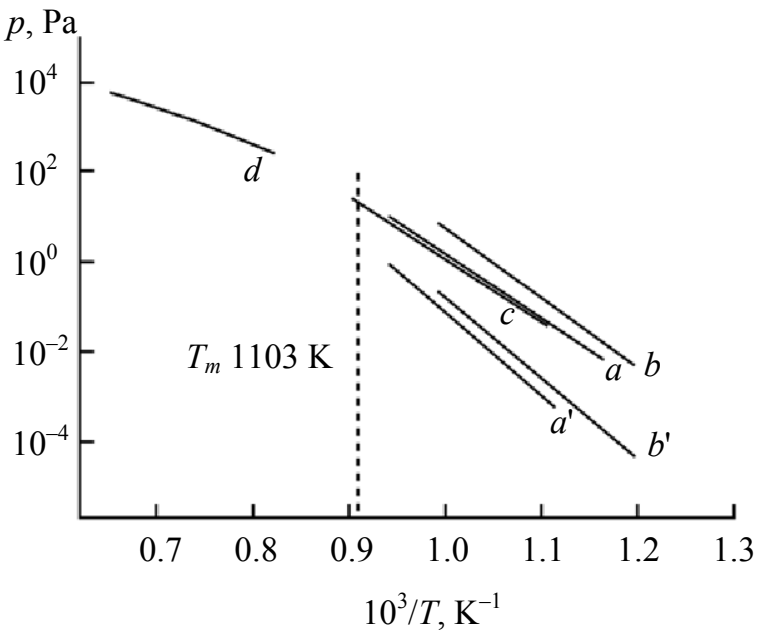

Fig. 2. Temperature dependences of vapor pressure above $\mathrm{TbBr}_{3}$ : $(a)$ monomer, $\left(a^{\prime}\right)$ dimer, this work, $(b)$ monomer, (b') dimer, [9], (c) [11], (d) [8,9].

uniform set of thermodynamic functions are presented in Table 4. In the calculation of the sublimation enthalpies of monomers the data of $[7,8,10,11]$ on total pressure were corrected for the vapor composition obtained from mass-spectrometry measurements. As a whole, as it is seen from Table 4, the values of sublimation enthalpies of monomers and dimers calculated by two independent methods using data of different authors agree within the limits of errors. The weighted average values (Table 5) found on the basis of criteria analysis [2] have been accepted as recommended values. As criteria (accepted equivalent) we have selected: (a) temperature run of the values of sublimation enthalpies calculated by Eq. (3); (b) comparison of sublimation entropies determined experimentally by Eq. (2) and calculated theoretically.

The enthalpies of formation of monomeric and dimeric molecules, which are presented in Table 5, were found by combining accepted values of the sublimation enthalpies and of the enthalpies of formation of gadolinium and terbium tribromides in the crystalline state [18].

Measurements of ionic sublimation in Knudsen mode. The ions $\mathrm{Br}^{-}, \mathrm{LnBr}_{4}^{-}$, and $\mathrm{Ln}_{2} \mathrm{Br}_{7}^{-}$were recorded for the both tribromides in the mass spectra of the ionic sublimation in the range $860-1070 \mathrm{~K}$. The ions $\mathrm{LnBr}_{4}^{-}$ were most intensive in the mass spectra, the intensity of the ions $\mathrm{Ln}_{2} \mathrm{Br}_{7}^{-}$was less by approximately an order of magnitude. The intensity of the current of the atomic ion $\mathrm{Br}^{-}$was from 2 up to $5 \%$ of the $\mathrm{LnBr}_{4}^{-}$ intensity. 
Table 3. Thermodynamic functions (A) $\Phi^{0}(T)\left(\mathrm{J} \mathrm{mol}^{-1} \mathrm{~K}^{-1}\right)$ and (B) $H^{0}(T)-H^{0}(0)\left(\mathrm{kJ} \mathrm{mol}^{-1}\right)$ used in calculations of sublimation enthalpies ${ }^{\mathrm{a}}$

\begin{tabular}{|c|c|c|c|c|c|c|c|c|c|c|}
\hline \multirow{2}{*}{$T, \mathrm{~K}$} & \multicolumn{2}{|c|}{$\mathrm{GdBr}_{3}$ (cr.) } & \multicolumn{2}{|c|}{$\mathrm{GdBr}_{3}$ (gas) } & \multicolumn{2}{|c|}{$\mathrm{Gd}_{2} \mathrm{Br}_{6}$ (gas) } & \multicolumn{2}{|c|}{$\mathrm{GdBr}_{4}^{-}$(gas) } & \multicolumn{2}{|c|}{$\mathrm{Gd}_{2} \mathrm{Br}_{7}^{-}$(gas) } \\
\hline & A & $\mathrm{B}^{\mathrm{b}}$ & A & B & A & B & A & B & A & B \\
\hline 298 & 189.96 & 0 & 333.42 & 20.49 & 514.78 & 44.63 & 367.90 & 26.58 & 540.89 & 51.27 \\
\hline 700 & 218.06 & 40.86 & 395.66 & 53.44 & 649.23 & 117.25 & 447.59 & 69.53 & 692.24 & 134.89 \\
\hline 800 & 226.27 & 51.36 & 405.91 & 61.71 & 672.16 & 135.46 & 461.19 & 80.28 & 718.13 & 155.84 \\
\hline 900 & 234.11 & 61.99 & 415.03 & 69.99 & 692.68 & 153.68 & 473.36 & 91.05 & 741.32 & 176.80 \\
\hline 1000 & 241.57 & 72.68 & 423.25 & 78.28 & 711.14 & 171.91 & 484.31 & 101.83 & 762.18 & 197.78 \\
\hline$T, \mathrm{~K}$ & \multicolumn{2}{|c|}{$\mathrm{TbBr}_{3}$ (cr.) $)^{\mathrm{b}}$} & \multicolumn{2}{|c|}{$\mathrm{TbBr}_{3}$ (gas) } & \multicolumn{2}{|c|}{$\mathrm{Tb}_{2} \mathrm{Br}_{6}$ (gas) } & \multicolumn{2}{|c|}{$\mathrm{TbBr}_{4}^{-}$(gas) } & \multicolumn{2}{|c|}{$\mathrm{Tb}_{2} \mathrm{Br}_{7}^{-}$(gas) } \\
\hline 298 & 194.02 & 0 & 337.48 & 20.45 & 527.58 & 45.55 & 372.36 & 26.53 & 554.92 & 52.29 \\
\hline 700 & 221.49 & 39.79 & 398.63 & 53.41 & 658.54 & 118.27 & 452.01 & 69.48 & 702.66 & 136.06 \\
\hline 800 & 229.45 & 49.89 & 409.10 & 61.68 & 681.16 & 136.48 & 465.61 & 80.24 & 728.17 & 157.02 \\
\hline 900 & 237.06 & 60.07 & 418.48 & 69.96 & 701.34 & 154.71 & 477.78 & 91.01 & 751.06 & 177.09 \\
\hline 1000 & 244.29 & 70.33 & 426.91 & 78.24 & 719.53 & 172.96 & 488.72 & 101.79 & 771.68 & 198.98 \\
\hline
\end{tabular}

a Errors in Gibbs energy functions were estimated by a procedure proposed in [14] and were accepted to be $(T=1000 \mathrm{~K}): \pm 12\left(\mathrm{LnBr}_{3}\right)$, $\pm 14\left(\mathrm{LnBr}_{4}^{-}\right), \pm 40\left(\mathrm{Ln}_{2} \mathrm{Br}_{6}\right)$, and $\pm 45 \mathrm{~J} \mathrm{~mol}^{-1} \mathrm{~K}^{-1}\left(\mathrm{Gd}_{2} \mathrm{Br}_{7}^{-}\right) .{ }^{\mathrm{b}} H^{0}(T)-H^{0}(298)$ is given.

Table 4. Values of enthalpies $\left(\mathrm{kJ} \mathrm{mol}^{-1}\right)$ and entropies $\left(\mathrm{J} \mathrm{mol}^{-1} \mathrm{~K}^{-1}\right)$ of $\mathrm{GdBr}_{3}$ sublimation in the form of monomeric and dimeric molecules determined by Eqs. (2) and (3) ${ }^{\mathrm{a}}$

\begin{tabular}{|c|c|c|c|c|c|c|c|c|}
\hline \multirow{2}{*}{$T, \mathrm{~K}$} & \multirow{2}{*}{$N$} & \multirow{2}{*}{$T_{\mathrm{cг}}$} & \multicolumn{3}{|c|}{ (2) } & \multicolumn{2}{|c|}{ (3) } & \multirow{2}{*}{ References } \\
\hline & & & $\Delta_{s} H^{0}\left(T_{\mathrm{cr}}\right)$ & $\Delta_{S} S^{0}\left(T_{\mathrm{cr}}\right)$ & $\Delta_{s} H^{0}(298 \mathrm{~K})$ & $\Delta_{s} H^{0}(298 \mathrm{~K})$ & $\Delta_{S} S^{0}\left(T_{\mathrm{cr}}\right)$ & \\
\hline \multicolumn{9}{|c|}{$\mathrm{GdBr}_{3}$ (cr.) $=\mathrm{GdBr}_{3}$ (gas) } \\
\hline $878-1044$ & 26 & 954 & $276.3 \pm 6.7$ & $191.3 \pm 7.1$ & $290.0 \pm 6.7$ & $288 \pm 12$ & $189 \pm 12$ & This work \\
\hline $854-1020$ & 45 & 937 & $261.6 \pm 3.8$ & $173.9 \pm 4.0$ & $274.9 \pm 3.8$ & $289 \pm 2$ & $189 \pm 12$ & [9] \\
\hline $895-1057$ & 102 & 976 & $271.0 \pm 3.8$ & $176.6 \pm 3.9$ & $285.3 \pm 3.8$ & $296 \pm 12$ & $188 \pm 12$ & {$[10]$} \\
\hline $1060-1179$ & 32 & 1120 & $229.0 \pm 3.8$ & $134.7 \pm 3.9$ & $287.0 \pm 3.8$ & $299 \pm 12$ & $137 \pm 12$ & \\
\hline $1220-1532$ & & 1376 & 203.8 & 116.2 & 276.3 & $301 \pm 12$ & $125 \pm 12$ & {$[7,8]$} \\
\hline $1200-1600$ & & 1400 & 198.0 & 114.2 & 277.6 & $300 \pm 12$ & $124 \pm 12$ & [11] \\
\hline \multicolumn{9}{|c|}{$2 \mathrm{GdBr}_{3}(\mathrm{cr})=.\mathrm{Gd}_{2} \mathrm{Br}_{6}$ (gas) } \\
\hline $907-1043$ & 21 & 967 & $358.8 \pm 10.9$ & $249.3 \pm 11.7$ & $375.8 \pm 10.9$ & $382 \pm 40$ & $255 \pm 40$ & This work \\
\hline $854-1020$ & 45 & 937 & $319.3 \pm 8.1$ & $206.7 \pm 7.7$ & $335.3 \pm 8.1$ & $382 \pm 40$ & $256 \pm 40$ & [9] \\
\hline \multicolumn{9}{|c|}{$\mathrm{TbBr}_{3}$ (cr.) $=\mathrm{TbBr}_{3}$ (gas) } \\
\hline $860-1064$ & 23 & 954 & $273.6 \pm 5.2$ & $180.7 \pm 7.7$ & $282.4 \pm 5.2$ & $296 \pm 12$ & $194 \pm 12$ & This work \\
\hline $836-1008$ & 102 & 922 & $279.6 \pm 3.8$ & $194.5 \pm 3.9$ & $290.6 \pm 3.8$ & $288 \pm 12$ & $192 \pm 2$ & [9] \\
\hline $904-1108$ & 127 & 1006 & 262.9 & 167.9 & 275.6 & $298 \pm 12$ & $190 \pm 12$ & {$[10]$} \\
\hline $1219-1536$ & & 1378 & 198.0 & 115.3 & 267.1 & $302 \pm 12$ & $140 \pm 12$ & {$[7,8]$} \\
\hline \multicolumn{9}{|c|}{$2 \mathrm{TbBr}_{3}$ (cr.) $=\mathrm{Tb}_{2} \mathrm{Br}_{6}$ (gas) } \\
\hline $898-1063$ & 15 & 985 & $353.5 \pm 7.1$ & $236.1 \pm 7.1$ & $367.6 \pm 7.1$ & $394 \pm 40$ & $264 \pm 40$ & This work \\
\hline $836-1008$ & 45 & 922 & $345.0 \pm 8.1$ & $233.8 \pm 7.7$ & $357.6 \pm 8.1$ & $385 \pm 40$ & $265 \pm 40$ & [9] \\
\hline
\end{tabular}

${ }^{a}(N)$ is the number of measurements; $\left(T_{\mathrm{av}}\right)$ average harmonic temperature, $T_{\mathrm{av}}=N / \Sigma\left(1 / T_{i}\right)$. In $[7,8,11]$ the saturated vapor pressure was measured above liquid $\mathrm{LnBr}_{3}$. For the values calculated by Eq. (2) with the sign " \pm " the standard deviation is given; by Eq. (3), the limiting error taking into account a statistical error and systematic errors in temperature, pressure, and reduced Gibbs energy functions. 
Table 5. Thermodynamic and kinetic parameters of sublimation and enthalpies of formation of molecules and ions $\left(\mathrm{kJ} \mathrm{mol}^{-1}\right)$

\begin{tabular}{l|c|c}
\hline \multicolumn{1}{c|}{ Parameter } & $\mathrm{Gd}$ & $\mathrm{Tb}$ \\
\hline$\Delta_{s} H^{\circ}\left(\mathrm{LnBr}_{3}\right.$, cr., $\left.298 \mathrm{~K}\right)$ & $294 \pm 5$ & $291 \pm 5$ \\
$\Delta_{s} H^{\circ}\left(\mathrm{Ln}_{2} \mathrm{Br}_{6}\right.$, cr., $\left.298 \mathrm{~K}\right)$ & $380 \pm 28$ & $391 \pm 28$ \\
$\Delta_{f} H^{\circ}\left(\mathrm{LnBr}_{3}\right.$, gas, 298 K) & $-544 \pm 6$ & $-553 \pm 6$ \\
$\Delta_{f} H^{\circ}\left(\mathrm{Ln}_{2} \mathrm{Br}_{6}\right.$, gas, $\left.298 \mathrm{~K}\right)$ & $-1296 \pm 30$ & $-1296 \pm 30$ \\
$\Delta_{\mathrm{s}} H^{\circ}\left(\mathrm{LnBr}_{4}^{-}\right.$, cr., $\left.T\right)$ & $273 \pm 12(900 \mathrm{~K})$ & $280 \pm 8(1000 \mathrm{~K})$ \\
$\Delta_{\mathrm{s}} H^{\circ}\left(\operatorname{Ln}_{2} \mathrm{Br}_{7}^{-}\right.$, cr., $\left.T\right)$ & $397 \pm 53(920 \mathrm{~K})$ & $386 \pm 11(1050 \mathrm{~K})$ \\
$\Delta_{f} H^{\circ}\left(\operatorname{LnBr}_{4}^{-}\right.$, gas, $\left.298 \mathrm{~K}\right)$ & $-1077 \pm 17^{\mathrm{a}}$ & $-1084 \pm 27$ \\
$\Delta_{f} H^{\circ}\left(\operatorname{Ln}_{2} \mathrm{Br}_{7}^{-}\right.$, gas, $\left.298 \mathrm{~K}\right)$ & $-1831 \pm 44$ & $-1832 \pm 44$ \\
$E_{\mathrm{a}}\left(\operatorname{LnBr}_{3}\right.$, cr., $\left.T\right)$ & $279 \pm 7(980 \mathrm{~K})$ & $283 \pm 7(1000 \mathrm{~K})$ \\
$E_{\mathrm{a}}\left(\operatorname{Ln}_{2} \mathrm{Br}_{6}\right.$, cr., $\left.T\right)$ & $397 \pm 15(970 \mathrm{~K})$ & $375 \pm 15(1000 \mathrm{~K})$ \\
$E_{\mathrm{a}}\left(\operatorname{LnBr}_{4}^{-}\right.$, cr., $\left.T\right)$ & $284 \pm 12(930 \mathrm{~K})$ & $305 \pm 18(1030 \mathrm{~K})$ \\
$E_{\mathrm{a}}\left(\operatorname{Ln}_{2} \mathrm{Br}_{7}^{-}\right.$, cr., $\left.T\right)$ & $383 \pm 32(935 \mathrm{~K})$ & $393 \pm 15(1035 \mathrm{~K})$ \\
\hline
\end{tabular}

${ }^{\text {a }}$ The value averaged over two reactions (Table 6 ) is given.

Enthalpies of sublimation of tribromides in the form of the $\mathrm{LnBr}_{4}^{-}$and $\mathrm{Ln}_{2} \mathrm{Br}_{7}^{-}$ions for the average temperature of the experiment were determined from the temperature dependences of ionic currents $\log I T^{1 / 2}=$ $f(1 / T)$, which are presented in Table 5. To determine the enthalpies of formation of $\mathrm{LnBr}_{4}^{-}$ions, a procedure based on measuring the equilibrium constant of gasphase ion-molecular reaction (4) for systems with various lanthanides $\mathrm{Ln}^{\mathrm{I}}$ and $\mathrm{Ln}^{\mathrm{II}}$ was used.

$$
\mathrm{Ln}^{\mathrm{I}} \mathrm{Br}_{3}+\operatorname{Ln}^{\mathrm{II}} \mathrm{Br}_{4}^{-}=\mathrm{Ln}^{\mathrm{II}} \mathrm{Br}_{3}+\mathrm{Ln}^{\mathrm{I}} \mathrm{Br}_{4}^{-} \text {. }
$$

In this reaction the ion $\mathrm{Ln}^{\mathrm{I}} \mathrm{Br}_{4}^{-}$acts as a standard, and the formation enthalpy of the ion $\mathrm{Ln}^{\mathrm{II}} \mathrm{Br}_{4}^{-}$was determined in relation to it.

To realize this procedure, we have studied the binary system $\mathrm{LuBr}_{3}-\mathrm{GdBr}_{3}$ and two ternary systems $\mathrm{LaBr}_{3}-\mathrm{GdBr}_{3}-\mathrm{LuBr}_{3}$ and $\mathrm{LaBr}_{3}-\mathrm{TbBr}_{3}-\mathrm{YbBr}_{3}$, using the enthalpies of formation of the $\mathrm{LuBr}_{4}^{-}$and $\mathrm{LaBr}_{4}^{-}$ ions as standards. The equilibrium constants of reactions (4) measured at various temperatures and the enthalpies of reactions (4) calculated by Eqs. (2) and (3) are presented in Table 6.

Enthalpies of formation of ions were determined on the basis of equilibrium constants measured of reaction (5) while studying pure gadolinium and terbium tribromide.

$$
\operatorname{Ln}_{2} \mathrm{Br}_{7}^{-} \text {(gas) }=\operatorname{LnBr}_{4}^{-} \text {(gas) }+\operatorname{LnBr}_{3} \text { (cr.). }
$$

Table 6. Experimental values of equilibrium constants and enthalpies of the ion-molecular reactions determined by

\begin{tabular}{|c|c|c|c|}
\hline Process $^{\mathrm{a}}$ & $T, \mathrm{~K}$ & $\ln K_{\mathrm{p}}^{0}$ & $\Delta_{\mathrm{r}} H^{0}(298 \mathrm{~K}), \mathrm{kJ} \mathrm{mol}^{-1}$ \\
\hline \multirow[t]{4}{*}{ I } & 877 & 2.174 & $-13.9 \pm 14.4(2)$ \\
\hline & 912 & 2.550 & $-16.6 \pm 5.0(3)$ \\
\hline & 944 & 2.440 & \\
\hline & 958 & 2.100 & \\
\hline \multirow[t]{8}{*}{ II } & 870 & -1.559 & $17.7 \pm 19.1(2)$ \\
\hline & 881 & -1.484 & $18.7 \pm 5.0$ \\
\hline & 902 & -1.333 & \\
\hline & 906 & -1.164 & \\
\hline & 922 & -1.354 & \\
\hline & 944 & -1.849 & \\
\hline & 950 & -1.024 & \\
\hline & 984 & -1.110 & \\
\hline \multirow[t]{6}{*}{ III } & 938 & 1.684 & $-10.3 \pm 9.2(2)$ \\
\hline & 976 & 1.458 & $-10.4 \pm 5.0$ \\
\hline & 994 & 1.663 & \\
\hline & 1017 & 1.317 & \\
\hline & 1040 & 1.268 & \\
\hline & 1152 & 1.451 & \\
\hline \multirow[t]{8}{*}{ IV } & 889 & 2.260 & $-90 \pm 62(2)$ \\
\hline & 893 & 4.135 & $-79 \pm 35(3)$ \\
\hline & 902 & 3.772 & \\
\hline & 909 & 2.585 & \\
\hline & 925 & 2.797 & \\
\hline & 934 & 2.940 & \\
\hline & 947 & 2.575 & \\
\hline & 970 & 2.113 & \\
\hline \multirow[t]{6}{*}{ V } & 1025 & 3.610 & $-96 \pm 30(2)$ \\
\hline & 1029 & 3.392 & $-96 \pm 35(3)$ \\
\hline & 1034 & 3.186 & \\
\hline & 1047 & 3.186 & \\
\hline & 1065 & 3.096 & \\
\hline & 1070 & 3.082 & \\
\hline
\end{tabular}
Eqs. (2) and (3)

a $\mathrm{GdBr}_{3}$ (gas) $+\mathrm{LaBr}_{4}{ }^{-}$(gas) $\rightarrow \mathrm{LaBr}_{3}$ (gas) $+\mathrm{GdBr}_{4}{ }^{-}$gas) (I); $\mathrm{GdBr}_{3}$ (gas) $+\mathrm{LuBr}_{4}^{-}$(gas) $\rightarrow \mathrm{LuBr}_{3}$ (gas) $+\mathrm{GdBr}_{4}^{-}$(gas) (II); $\mathrm{TbBr}_{3}$ (gas) $+\mathrm{LaBr}_{4}^{-}$(gas) $\rightarrow \mathrm{LaBr}_{3}$ (gas) $+\mathrm{TbBr}_{4}^{-}$(gas) (III); $\mathrm{Gd}_{2} \mathrm{Br}_{7}^{-}$(gas) $\rightarrow \mathrm{GdBr}_{3}$ (cr.) $+\mathrm{GdBr}_{4}^{-}$(gas) (IV); $\mathrm{Tb}_{2} \mathrm{Br}_{7}^{-}$(gas) $\rightarrow$ $\mathrm{TbBr}_{3}$ (cr.) $+\mathrm{TbBr}_{4}^{-}$(gas) (V).

The input data and the results of their processing are presented in Table 6 .

Thermodynamic functions of $\mathrm{LnBr}_{4}^{-}$and $\mathrm{Ln}_{2} \mathrm{Br}_{7}^{-}$ ions in the ideal gas state (Table 3) necessary for the calculations were calculated by the procedure given in [2]. The enthalpies of formation of $\mathrm{LnBr}_{4}^{-}$and $\mathrm{Ln}_{2} \mathrm{Br}_{7}^{-}$ 


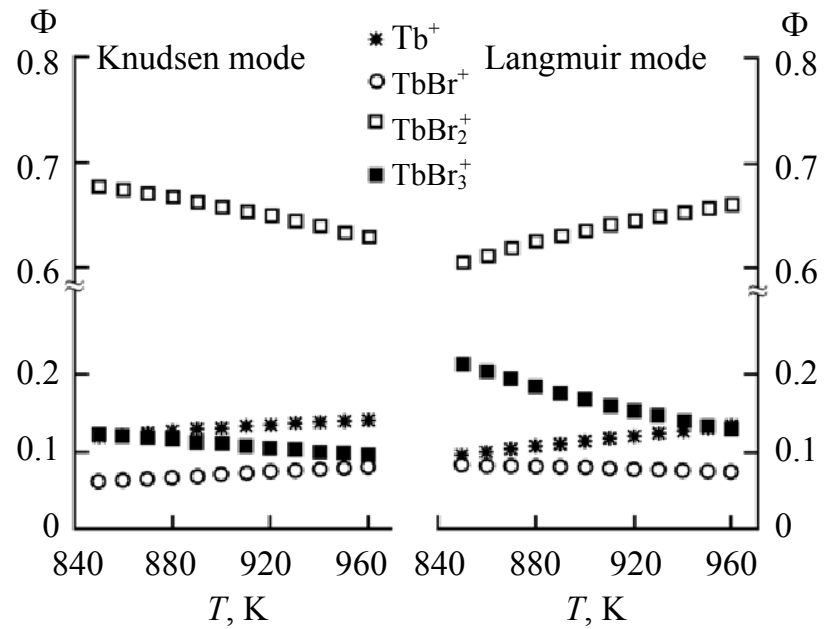

Fig. 3. Temperature dependence of relative partial ionization cross sections $\Phi$ in Knudsen and Langmuir sublimetion modes (using the $\mathrm{TbBr}_{3}$ molecule as an example).

ions (Table 5) were determined on the basis of the obtained enthalpies of reactions (4) and (5) [Eq. (3)] and also of the enthalpies of formation $\Delta_{\mathrm{f}} H^{0}(298 \mathrm{~K})$ of gaseous molecules and ions in gas state $\{-538 \pm 15$ $\left(\mathrm{LuBr}_{3}\right),-584 \pm 10\left(\mathrm{LaBr}_{3}\right),-1085 \pm 23\left(\mathrm{LuBr}_{4}^{-}\right)$, and $\left.-1105 \pm 14\left(\mathrm{LaBr}_{4}^{-}\right)[2]\right\}$ and in crystals $\{-838.2 \pm 2.0$ $\left.\left(\mathrm{GdBr}_{3}\right),-843.5+3.0 \mathrm{~kJ} \mathrm{~mol}^{-1}\left(\mathrm{TbBr}_{3}\right)[18]\right\}$.

Measurements in Langmuir mode. The mass spectra of molecular sublimation, except for the $\mathrm{Tb}_{3} \mathrm{Br}_{8}^{+}$ion, which was not recorded in this mode, are identical in qualitative composition to the corresponding mass spectra of the vapor above the studied tribromides observed in Knudsen mode. At the same time essential differences both in relative intensities of ionic currents and in their temperature dependences are observed. The aforesaid is readily illustrated by Fig. 3, where temperature dependences of relative partial ionization cross sections $\Phi$ (ratio of the current of ions of a specified type to a total current of all ions formed from a given molecule) for single-charged ions are presented. We have noted an analogous effect also for others tribromides [1-6]. In our opinion its nature is connected with essential polarization of adsorbed molecules in the field of the surface charge of the ionic crystal resulted in an excess "superthermal" vibrationrotation excitation of molecules sublimated from a crystal open surface [2].

Activation energies of sublimation of crystals of the studied tribromides in the form of monomeric and dimeric molecules and $\mathrm{LnBr}_{4}^{-}$and $\mathrm{Ln}_{2} \mathrm{Br}_{7}^{-}$ions were determined for an average experimental temperature

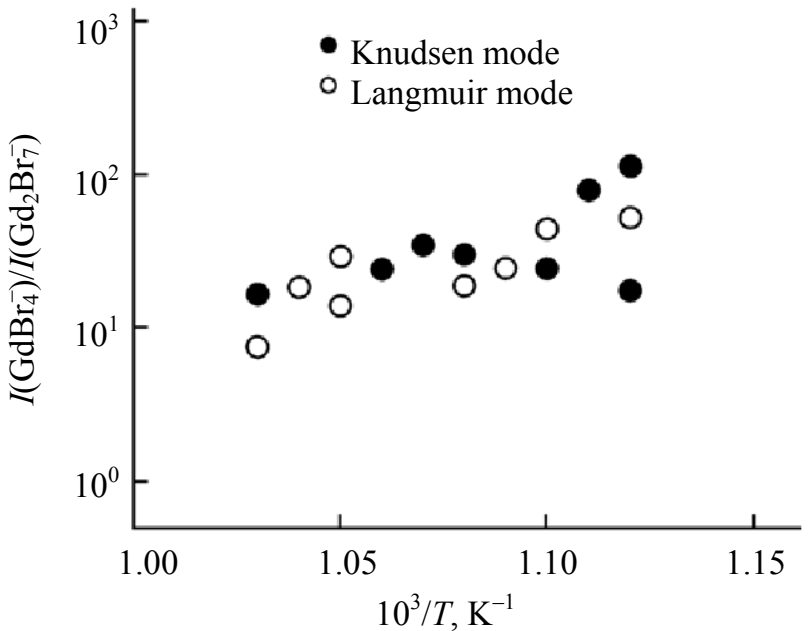

Fig. 4. Temperature dependence of the ratio of intensities of ionic currents $I\left(\mathrm{GdBr}_{4}^{-}\right) /\left(\mathrm{Gd}_{2} \mathrm{Br}_{7}^{-}\right)$in Knudsen and Langmuir sublimation modes.

from slopes of temperature dependences of ionic currents $\log \left[\Sigma I_{i} T /\left(a_{i} \gamma_{i}\right)\right]-1 / T\left(i: \mathrm{Ln}^{+}, \mathrm{LnBr}^{+}, \mathrm{LnBr}_{2}{ }^{+}\right.$, $\mathrm{LnBr}_{3}^{+}, \mathrm{Ln}^{++}, \mathrm{LnBr}^{++}$, and $\mathrm{LnBr}_{2}^{++}$are monomers; $i$ : $\mathrm{Ln}_{2} \mathrm{Br}_{4}^{+}, \mathrm{Ln}_{2} \mathrm{Br}_{5}^{+}$are dimers) and $\log I_{i} T^{1 / 2}-1 / T(i$ : $\mathrm{LnBr}_{4}^{-}$and $\mathrm{Ln}_{2} \mathrm{Br}_{7}^{-}$), which are presented in Table 5 .

Comparison of sublimation activation energies and enthalpies for the studied tribromides shows that the enthalpies of monomeric molecules $\mathrm{LnBr}_{3}$ and $\mathrm{LnBr}_{4}^{-}$ ions are close in values, and within the error limits they can be considered as equal. A similar correspondence is observed also for the corresponding parameters of the sublimation in the form of $\mathrm{Ln}_{2} \mathrm{Br}_{6}$ dimeric molecules and $\mathrm{Ln}_{2} \mathrm{Br}_{7}^{-}$ions. Whereas the activation energies and enthalpies of the sublimation in the form of monomeric and dimeric molecules are close to each other, the ratio of dimeric and monomeric molecules has appeared to be higher on the evaporation in Knudsen mode. This experimental fact reflects differences in the sublimation coefficients of dimers $\alpha_{s}\left(\operatorname{Ln}_{2} B_{6}\right)$ and monomers $\alpha_{s}\left(\operatorname{LnBr}_{3}\right)$. On the basis of relative intensities of ionic currents measured in two sublimation modes, we have estimated the ratio of partial sublimation coefficients $\alpha_{s}\left(\operatorname{LnBr}_{3}\right) / \alpha_{s}\left(\operatorname{Ln}_{2} \mathrm{Br}_{6}\right)$ for the studied tribromides at factors $15.7\left(\mathrm{GdBr}_{3}\right)$ and $2.2\left(\mathrm{TbBr}_{3}\right)$. We note that of all studied tribromides [1-6] the greatest decrease in the fraction of dimers is observed for $\mathrm{GdBr}_{3}$ on passing from Knudsen mode to Langmuir mode.

Assumed reasons of the decrease in the oligomerization degree of molecular flows in Langmuir mode can be a damped surface diffusion of adsorbed 
Table 7. Input data and results of calculation of electron work function for $\mathrm{LnBr}_{3}$ crystals

\begin{tabular}{|c|c|c|c|}
\hline \multirow{2}{*}{ Process } & \multirow{2}{*}{ Parameter } & \multicolumn{2}{|c|}{ Value, $\mathrm{kJ} \mathrm{mol}^{-1 \mathrm{a}}$} \\
\hline & & $\mathrm{GdBr}_{3}$ & $\mathrm{TbBr}_{3}$ \\
\hline $\mathrm{LnBr}_{4}^{-}$(in a matrix template of $\mathrm{LnBr}_{3}$ crystals $)=\mathrm{LnBr}_{4}^{-}$(gas) & $\Delta_{\mathrm{s}} H_{i}^{0}$ & $273 \pm 12$ & $280 \pm 8$ \\
\hline $\mathrm{LnBr}_{3}(\mathrm{cr})=.\mathrm{LnBr}_{3}$ (gas) & $\Delta_{\mathrm{S}} H^{0}$ & $281 \pm 10$ & $278 \pm 10$ \\
\hline $\mathrm{LnBr}_{4}^{-}($gas $)=\mathrm{Br}^{-}($gas $)+\mathrm{LnBr}_{3}$ (gas) & $\Delta_{\mathrm{r}} H^{0}$ & $307 \pm 18$ & $309 \pm 26$ \\
\hline $\mathrm{LnBr}_{3}($ gas $)=\mathrm{Ln}($ gas $)+3 \mathrm{Br}($ gas $)$ & $\Delta_{\mathrm{at}} H^{0}$ & $1282 \pm 12$ & $1279 \pm 12$ \\
\hline $\mathrm{Br}($ gas $)+\mathrm{e}^{-}=\mathrm{Br}^{-}$(gas) & $A_{0}$ & \multicolumn{2}{|c|}{$324.7 \pm 0.3[20]$} \\
\hline$\varphi_{\mathrm{e}}, \mathrm{eV}$ & & $2.6 \pm 0.2$ & $2.8 \pm 0.2$ \\
\hline
\end{tabular}

${ }^{\mathrm{a}}$ Presented values refer to the average temperature of the studied ranges: $900 \mathrm{~K}\left(\mathrm{GdBr}_{3}\right)$ and $1000 \mathrm{~K}\left(\mathrm{TbBr}_{3}\right)$.

molecules of dimers as compared with monomers owing to their greater polarizability and also a retardation of rotation and distortion of molecular structure in an electric field of a crystal surface charge [2].

A special feature of the ionic sublimation study is the fact that in the studied temperature range (Fig. 4) the ratio of ionic currents $I\left(\mathrm{LnBr}_{4}^{-}\right) / I\left(\mathrm{Ln}_{2} \mathrm{Br}_{7}^{-}\right)$is independent of a sublimation mode. This result confirms the assumption [2] about the "diffusionless" mechanism of sublimation of ionic associates.

Electron work function. The ion $\mathrm{LnBr}_{4}^{-}$was most intensive in the thermoionic emission mass spectrum. Emission of $\mathrm{LnBr}_{4}^{-}$was observed in rather wide temperature ranges that has allowed us to determine reliably the values of sublimation enthalpies $\left(\Delta_{\mathrm{s}} H_{i}^{0}\right)$ of the studied tribromides in the form of $\mathrm{LnBr}_{4}^{-}$ions and to calculate the electron work function for $\mathrm{LnBr}_{3}$ crystals by Eq. (6) [19].

$$
\varphi_{\mathrm{e}}=\Delta_{\mathrm{s}} H_{i}^{0}-1 / 4 \Delta_{\mathrm{at}} H^{0}-5 / 4 \Delta_{\mathrm{s}} H^{0}+A_{0}+\Delta_{\mathrm{r}} H^{0} .
$$

Here $\Delta_{\mathrm{at}} H^{0}$ is the enthalpy of the reaction of $\mathrm{LnBr}_{3}$ atomization, $A_{0}$ is the bromine atom electron affinity, and $\Delta_{\mathrm{r}} H^{0}$ is the enthalpy of gas-phase reaction (7).

$$
\mathrm{LnBr}_{4}^{-}=\mathrm{Br}^{-}+\mathrm{LnBr}_{3} \text {. }
$$

Input data and results of the $\varphi_{e}$ calculation are presented in Table 7. The resulting values of the electron work function are thermodynamically reversible effective parameters related to the average temperature of the studied ranges.

\section{EXPERIMENTAL}

The work was fulfilled on an MI 1201 massspectrometer adapted for high-temperature investigations at the energy of ionizing electrons $70 \mathrm{eV}$. An energy scale of ionizing electrons was calibrated using the ionization energy of silver atoms and water molecules as standards [20]. The error in appearance energies was estimated at $\pm 0.5 \mathrm{eV}$ for single-charged and $\pm 1 \mathrm{eV}$ for two-charge ions. The detailed description of the installation and experimental techniques is given in [1].

Samples under study of $99.99 \%$ purity were evaporated from a molybdenum cell with the ratio of a sectional area to the effusion orifice area $(d 0.6 \mathrm{~mm})$ of about 400. In Langmuir mode $\mathrm{GdBr}_{3}$ and $\mathrm{TbBr}_{3}$ single crystals were fixed in a molybdenum holder; the (001) face of a crystal $(3 \times 3 \mathrm{~mm})$ obtained by spalling directly before placing of an evaporator in the massspectrometer was exposed for sublimation.

\section{ACKNOWLEDGMENTS}

This work was financially supported by the Russian Foundation for Basic Research (project no. 09-0300315-a).

\section{REFERENCES}

1. Butman, M.F., Motalov, V.B., Kudin, L.S., Grishin, A.E., Kryuchkov, A.S., and Kremer, K.V., Zh. Fiz. Khim., 2008, vol. 82, no. 2, p. 227.

2. Butman, M.F., Kudin, L.S., Motalov, V.B., Vorob'ev, D.E., Grishin, A.E., Kryuchkov, A.S., and Kremer, K.V., $Z h$. Fiz. Khim., 2008, vol. 82, no. 4, p. 631.

3. Kudin, L.S., Butman, M.F., Motalov, V.B., Grishin, A.E., Kryuchkov, A.S., and Bergman, G.A., Teplofiz. Vys. Temp., 2008, vol. 46, no. 3, p. 388.

4. Butman, M.F., Motalov, V.B., Kudin, L.S., Kryuchkov, A.S., Grishin, A.E., and Kremer, K.V., Zh. Fiz. Khim., 2009, vol. 83, no. 1, p. 152. 
5. Butman, M.F., Kudin, L.S., Motalov, V.B., Kryuchkov, A.S., Grishin, A.E., and Kremer, K.V., Zh. Fiz. Khim., 2009, vol. 83, no. 2, p. 220.

6. Kudin, L.S., Butman, M.F., Motalov, V.B., Nakonechnyi, S.N., and Kremer, K.V., Zh. Neorg. Khim., 2009, vol. 54, no. 8, p. 1245.

7. Makhmadmurodov, A., Dudchik, G.P., and Polyachonok, O.G., J. Phys. Chem., 1975, vol. 49, no. 10, p. 1599.

8. Makhmadmurodov, A., Temurova, M., and Sharipov, A., Izv. Akad. Nauk Tadzhikskoi SSR, Otd. Fiz-mat., Khim. i Geol. Nauk, 1989, vol. 111, no. 1, p. 39.

9. Gietmann, C., Hilpert, K., and Nickel, H., Thermodynamische Eigenschaften von Halogeniden der Lanthaniden, Forschungszentrum Julich, 1997.

10. Piacente, V., Scardala, P., and Brunetti, B., J. Chem. Eng. Data, 2003, vol. 48, no. 3. p. 637.

11. Weigel, F. and Gabriele Trinkl, G., Z. Anorg. Allg. Chem., 1970, vol. 377, no. 3, p. 228.

12. Hilpert, K., Chemistry of Inorganic Vapors, in Structure and Bonding 73, Clarke M., Goodenough, J.B., and Ibers, J.A., Eds., Berlin: Springer-Verlag, 1990, p. 97.
13. Mann, J.B., Recent Developments in Mass Spectrometry, Ogata, K. and Haykawa, T., Eds., Tokyo: University of Tokyo Press, 1970, p. 814.

14. Termodinamicheskie svoistva individual'nykh veshchestv (Thermodynamic Properties of Pure Substances), Glushko, V.P., Ed., Moscow: Nauka, 1978-1984.

15. Rycerz, L. and Gaune-Escard, M., J. Chem. Eng. Data, 2004, vol. 49, no. 4, p. 1078.

16. Bergman, G.A., Baza dannukh IVTANTERMO-2009 (Database IVTANTERMO-2009).

17. Kovács, A. and Konings, R.J.M., J. Phys. Chem. Ref. Data, 2004, vol. 33, no. 1, p. 377.

18. Cordfunke, E.H.P. and Konings, R.J.M., Thermochim. Acta, 2001, vol. 375, p. 17.

19. Butman, M.F., Kudin, L.S., Grishin, A.E., Kryuchkov, A.S., and Sergeev, D.N., Zh. Fiz. Khim., 2008, vol. 82, no. 3, p. 545 .

20. Energii razryva khimicheskikh svyazei. Potentsialy ionizatsii $i$ srodstvo $k$ elektronu (Energies of Breaking Chemical Bonds: Ionization Potentials and Electron Affinities), Kondrat'ev, V.N., Ed., Moscow: Nauka, 1974. 